\title{
Metabolic Profiling of the Novel Hypoxia-Inducible Factor $2 \alpha$ Inhibitor PT2385 In Vivo and In Vitro ${ }^{\mathbb{S}}$
}

\author{
Cen Xie, ${ }^{1}$ Xiaoxia Gao, ${ }^{1}$ Dongxue Sun, ${ }^{2}$ Youbo Zhang, ${ }^{3}$ Kristopher W. Krausz, Xuemei Qin, \\ and Frank J. Gonzalez
}

Laboratory of Metabolism, Center for Cancer Research, National Cancer Institute, National Institutes of Health, Bethesda, Maryland (C.X., X.G., D.S., Y.Z., K.W.K., F.J.G.); and Modern Research Center for Traditional Chinese Medicine, Shanxi University, Taiyuan, Shanxi, People's Republic of China (X.G., X.Q.)

Received November 27, 2017; accepted January 18, 2018

\begin{abstract}
PT2385 is a first-in-class, selective small-molecule inhibitor of hypoxia-inducible factor-2 $\alpha$ (HIF-2 $\alpha$ ) developed for the treatment of advanced clear cell renal cell carcinoma. Preclinical results demonstrated that PT2385 has potent antitumor efficacy in mouse xenograft models of kidney cancer. It also has activity toward metabolic disease in a mouse model. However, no metabolism data are currently publically available. It is of great importance to characterize the metabolism of PT2385 and identify its effect on systemic homeostasis in mice. High-resolution mass spectrometry-based metabolomics was performed to profile the biotransformation of PT2385 and PT2385-induced changes in endogenous metabolites. Liver microsomes and recombinant drug-metabolizing enzymes were used to determine the mechanism of PT2385 metabolism. Real-time polymerase chain reaction analysis was employed to investigate the reason
\end{abstract}

for the PT2385-induced bile acid dysregulation. A total of 12 metabolites of PT2385 was characterized, generated from hydroxylation (M1, M2), dihydroxylation and desaturation (M3, M4), oxidativedefluorination (M7), glucuronidation (M8), $\mathrm{N}$-acetylcysteine conjugation (M9), and secondary methylation (M5, M6) and glucuronidation (M10, M11, and M12). CYP2C19 was the major contributor to the formation of M1, M2, and M7, UGT2B17 to M8, and UGT1A1/3 to M10-M12. The bile acid metabolites taurocholic acid and tauro$\boldsymbol{\beta}$-muricholic acid were elevated in serum and liver of mice after PT2385 treatment. Gene expression analysis further revealed that intestinal HIF-2 $\alpha$ inhibition by PT2385 treatment upregulated the hepatic expression of CYP7A1, the rate-limiting enzyme in bile acid synthesis. This study provides metabolic data and an important reference basis for the safety evaluation and rational clinical application of PT2385.

\section{Introduction}

It has been estimated that nearly 63,990 new cases of kidney cancer will be diagnosed and more than 14,400 people will die from this disease in 2017 (Siegel et al., 2017). Clear cell renal cell carcinoma (ccRCC) is the most common kidney cancer, representing $70 \%-75 \%$ of all primary renal cell malignancies (Muglia and Prando, 2015). In more than $90 \%$ of ccRCC patients, von Hippel-Lindau (VHL) protein is defective, leading to the activation of hypoxia-inducible factor (HIF)- $\alpha$ (Gnarra et al.,

This work was supported by the Intramural Research Program of the National Institutes of Health (National Cancer Institute) and the National Natural Science Foundation of China [Grants 81473415 and 81403007 ]. X.G. was supported by Shanxi University.

${ }^{1}$ C.X. and X.G. are co-first authors.

${ }^{2}$ Current affiliation: College of Traditional Chinese Medicine, Shenyang Pharmaceutical University, Shenyang, Liaoning, China.

${ }^{3}$ Current affiliation: State Key Laboratory of Natural and Biomimetic Drugs (Peking University) and Department of Natural Medicines, School of Pharmaceutical Sciences, Peking University, Beijing, China.

https://doi.org/10.1124/dmd.117.079723.

S This article has supplemental material available at dmd.aspetjournals.org.
1994; Sato et al., 2013). The HIF- $\alpha$ family, consisting of HIF- $1 \alpha$, HIF$2 \alpha$, and the less well-characterized HIF- $3 \alpha$, is an oxygen-sensitive transcription factor family that regulates anaerobic metabolism, energy metabolism, angiogenesis, cell proliferation, differentiation, and survival (Semenza and Wang, 1992; Keith et al., 2011). HIF- $\alpha$ levels are regulated by a ubiquitin-proteasome degradation pathway mediated by the E3 ubiquitin ligase VHL, and by the action of prolyl hydroxylase enzymes that hydroxylate the oxygen-sensing subunit of HIF- $\alpha$, leading to recognition by VHL and ultimate degradation (Maxwell et al., 1999; Epstein et al., 2001). Over the past decades, accumulating data revealed an oncogenic role for HIF- $2 \alpha$ in VHL-defective ccRCC and highlighted the therapeutic potential of HIF- $2 \alpha$ antagonism in ccRCC treatment (Kondo et al., 2002; Gordan et al., 2007; Bertout et al., 2009; Vanharanta et al., 2013).

PT2385, [S]-3((2,2-difluoro-1-hydroxy-7-(methylsulfonyl)-2,3dihydro-1H-inden-4-yl)oxy)-5-fluorobenzonitrile (Fig. 1), is a selective and potent small-molecule HIF- $2 \alpha$ inhibitor identified by a structure-based design approach. It allosterically blocks the heterodimerization of HIF-2 $\alpha$ with its partner aryl hydrocarbon receptor nuclear translocator/HIF- $1 \beta$, while having no effect on HIF- $1 \alpha$ (Wallace et al., 2016). Preclinical data revealed that PT2385 treatment suppresses gene

ABBREVIATIONS: ccRCC, clear cell renal cell carcinoma; CYP, cytochrome P450; FMO, flavin-containing mono-oxygenase; FXR, farnesoid X receptor; HIF, hypoxia-inducible factor; HLM, human liver microsome; HRMS, high resolution mass spectrometer; IS, internal standard; MLM, mice liver microsome; MS/MS, mass spectrometry/mass spectrometry; OPLS-DA, orthogonal projections to latent structures discriminant analysis; PCA, principle components analysis; Q/TOF MS, quadrupole/time-of-flight mass spectrometer; T- $\beta$-MCA, tauro- $\beta$-muricholic acid; TCA, taurocholic acid; UDPGA, uridine $5^{\prime}$-diphosphoglucuronic acid trisodium salt; UGT, UDP-glucuronosyltransferase; UPLC, ultraperformance liquid chromatography; VHL, von Hippel-Lindau. 

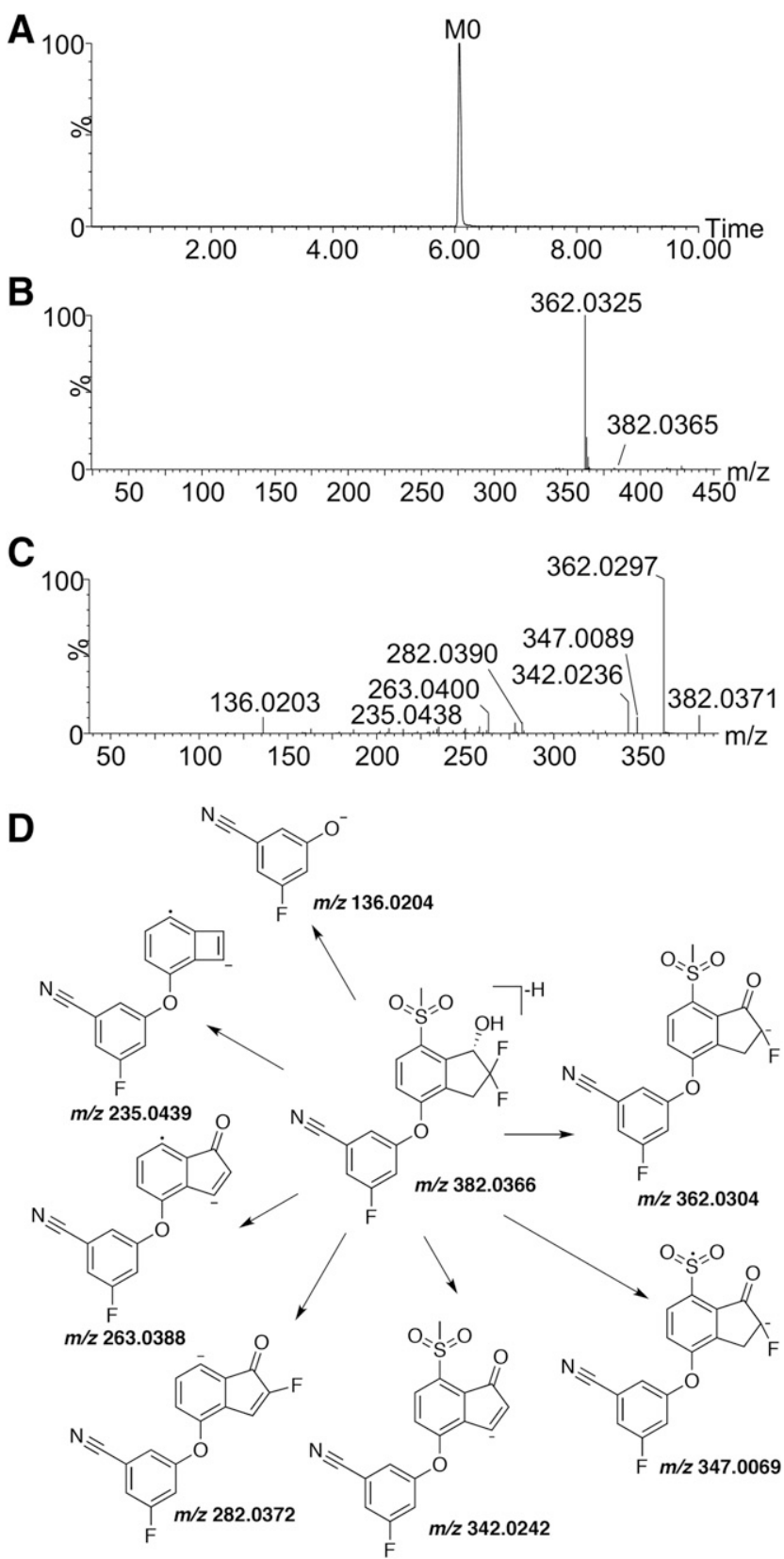

Fig. 1. Chromatography and mass spectra of PT2385 by UPLC-HRMS analysis. (A) Chromatographic graph of PT2385; (B) mass spectrum of PT2385 in negative mode. (C) MS/MS spectrum of PT2385 in negative mode. (D) Tentative MS/MS fragmentation pattern of PT2385.

expression essential for tumor growth, proliferation, and angiogenesis in ccRCC cell lines and in tumor xenografts. In ccRCC mouse models, PT2385 also inhibits tumor growth and displays better efficacy than sunitinib, a currently approved first-line anti-angiogenesis drug, without cardiovascular adverse effects (Wallace et al., 2016). Similarly, the structural analog PT2399 also causes tumor regression in mouse models of primary and metastatic pVHL-defective ccRCC and patient-derived xenografts (Chen et al., 2016; Cho et al., 2016). Phase I results demonstrated that PT2385 is well tolerated and showed promising efficacy in a highly pretreated patient population (Chen et al., 2016; Courtney et al., 2017). PT2385 is currently under evaluation in a phase II clinical trial for the treatment of ccRCC. The primary objective of this trial is to examine the overall response rate of VHL-associated ccRCC tumors in untreated patients. There is another phase II study of PT2385 for patients with recurrent glioblastoma. Besides antineoplastic activity, a recent report also showed that the inhibition of intestinal HIF- $2 \alpha$ signaling by PT2385 substantially prevents and reverses obesity, insulin resistance, and hepatic steatosis in mice (Xie et al., 2017).

To fully characterize the efficacy and safety of drug candidates, the metabolism must be determined during drug discovery and development (Xie et al., 2012). The profiling of endogenous metabolism is also helpful in understanding the action of a drug on the organism. Metabolomics is a promising tool to determine the metabolic fate of a drug and alterations of endogenous substances that can serve as biomarkers for drug efficacy and toxicity (Fang and Gonzalez, 2014). In this study, ultraperformance liquid chromatography (UPLC) highresolution mass spectrometry (HRMS)-based metabolomics was applied to elucidate PT2385 metabolism and interactions, including identification of metabolites, the major drug-metabolizing enzymes involved, and its influence on bile acid homeostasis, through combining in vitro incubation studies and in vivo animal models.

\section{Materials and Methods}

Chemicals and Reagents. PT2385 was purchased from MedChem Express (Monmouth Junction, NJ). NADPH, uridine diphosphate glucuronic acid (UDPGA), taurocholic acid (TCA), tauro- $\beta$-muricholic acid (T- $\beta$-MCA), and alamethicin were purchased from Sigma-Aldrich (St. Louis, MO). All other reagents were of the highest grade commercially available. Livers from untreated 6-week-old male C57BL/6N mice were used to prepare mouse liver microsomes (MLMs), as previously described (Meijer et al., 1987). Human liver microsomes (HLMs), recombinant cytochromes P450s (CYPs; 1A1, 1A2, 1B1, 2A6, 2B6, 2C8, 2C9, 2C19, 2D6, 2E1, 3A4, 3A5, and 4A11), flavin-containing mono-oxygenases (FMOs; FMO1, FMO3, and FMO5), and UDPglucuronosyltransferase (UGTs; 1A1, 1A3, 1A4, 1A6, 1A9, 2B4, 2B7, 2B10, 2B15, and 2B17) were purchased from Corning Life Sciences (Tewksbury, MA).

Animals. Male C57BL/6N mice were obtained from Charles River Laboratories (Wilmington, MA). Male Hif2 $a^{\mathrm{fl} / \mathrm{fl}}$ (control) and Hif $2 a^{\Delta \mathrm{IE}}$ (intestine-specific Hif2a disruption) mice were generated and maintained, as previously described (Xie et al., 2017). Mice were housed in a temperature- and humidity-controlled room and maintained under a standard 12-hour light/12-hour dark cycle, with water and chow provided ad libitum. Mouse handling was performed in accordance with an animal study protocol approved by the National Cancer Institute Animal Care and Use Committee.

Seven male C57BL/6N (6- to 8-week-old) mice were divided into a control group $(n=4)$ and PT2385-treated group $(n=3)$. PT2385, suspended in $0.5 \%$ sodium carboxymethyl cellulose, $2.5 \%$ Tween 80 , and $2.5 \%$ dimethyl sulfoxide, was given by oral gavage at a dose of $50 \mathrm{mg} / \mathrm{kg}$ body weight, and control mice were treated with vehicle ( $0.5 \%$ sodium carboxymethyl cellulose, $2.5 \%$ Tween 80 , and $2.5 \%$ dimethylsulfoxide). Urine and feces samples were collected for 24 hours after administration. Blood samples were collected by retro-orbital bleeding at 3 and 24 hours, respectively. After centrifugation for 10 minutes at $8000 \mathrm{~g}$, serum was obtained for metabolite analysis. Gallbladder, intestine mucosa, and liver samples were collected after the mice were killed. Following centrifugation for 10 minutes at $15,000 \mathrm{~g}$, bile samples were collected. Liver samples were also collected from 12-week-old male littermate $H$ if $2 a^{\mathrm{f} / f 1}$ and Hif $2 a^{\Delta \mathrm{IE}}$ mice ( $n=5 /$ group), respectively. All samples were stored at $-80^{\circ} \mathrm{C}$ until analysis.

Sample Preparation. For sample preparation, $30 \mu 1$ serum was deproteinizated with $60 \mu \mathrm{l}$ acetonitrile containing $2 \mu \mathrm{M}$ chlorpropamide [internal standard (IS)]. After centrifugation for 10 minutes at $15,000 g, 50 \mu \mathrm{l}$ supernatant was diluted with $50 \mu \mathrm{l}$ water containing $0.1 \%$ formic acid. Urine samples were prepared by mixing $30 \mu \mathrm{l}$ urine with $60 \mu \mathrm{l} 66 \%$ aqueous acetonitrile containing $2 \mu \mathrm{M}$ IS. The feces were pulverized, and $1 / 20(\mathrm{wt} / \mathrm{v}) 66 \%$ aqueous acetonitrile ( $2 \mu \mathrm{M}$ IS) was added for extraction, followed by centrifugation. An aliquot of $2 \mu \mathrm{l}$ bile was deproteinizated with $200 \mu \mathrm{l}$ acetonitrile containing $2 \mu \mathrm{M}$ IS. After centrifugation for 10 minutes at $15,000 \mathrm{~g}$, the supernatants were diluted with $800 \mu \mathrm{l}$ water containing $0.1 \%$ formic acid. All samples were centrifuged at $15,000 \mathrm{~g}$ for 10 minutes, and $5 \mu \mathrm{l}$ aliquot of the supernatants was injected into a 

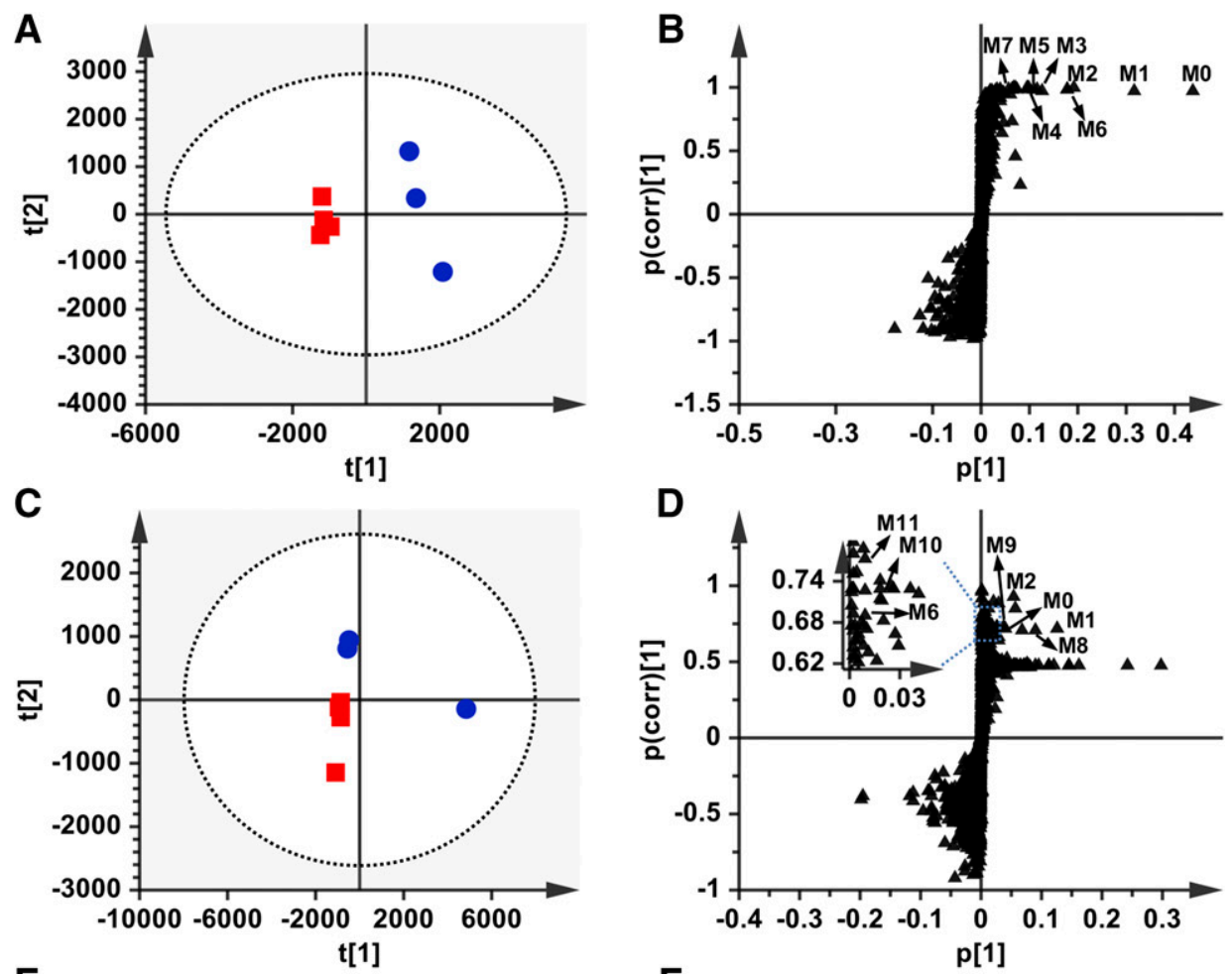

Fig. 2. Multivariate data analysis and PT2385 metabolite identification. Samples were collected from mice 24 hours after orally administered with vehicle or PT2385 at a single dose of $50 \mathrm{mg} / \mathrm{kg}$. (A and B) PCA score plot (A) and S-plot (B) of feces metabolome. (C and D) PCA score plot (C) and S-plot (D) of urine metabolome. (E and F) PCA score plot (E) and S-plot (F) of bile metabolome. (G and H) PCA score plot $(\mathrm{G})$ and S-plot (H) of 3-hour serum metabolome. Vehicle (घ) and PT2385 (@). Each point represents an individual mouse sample in PCA score plot and a unique ion in S-plot.
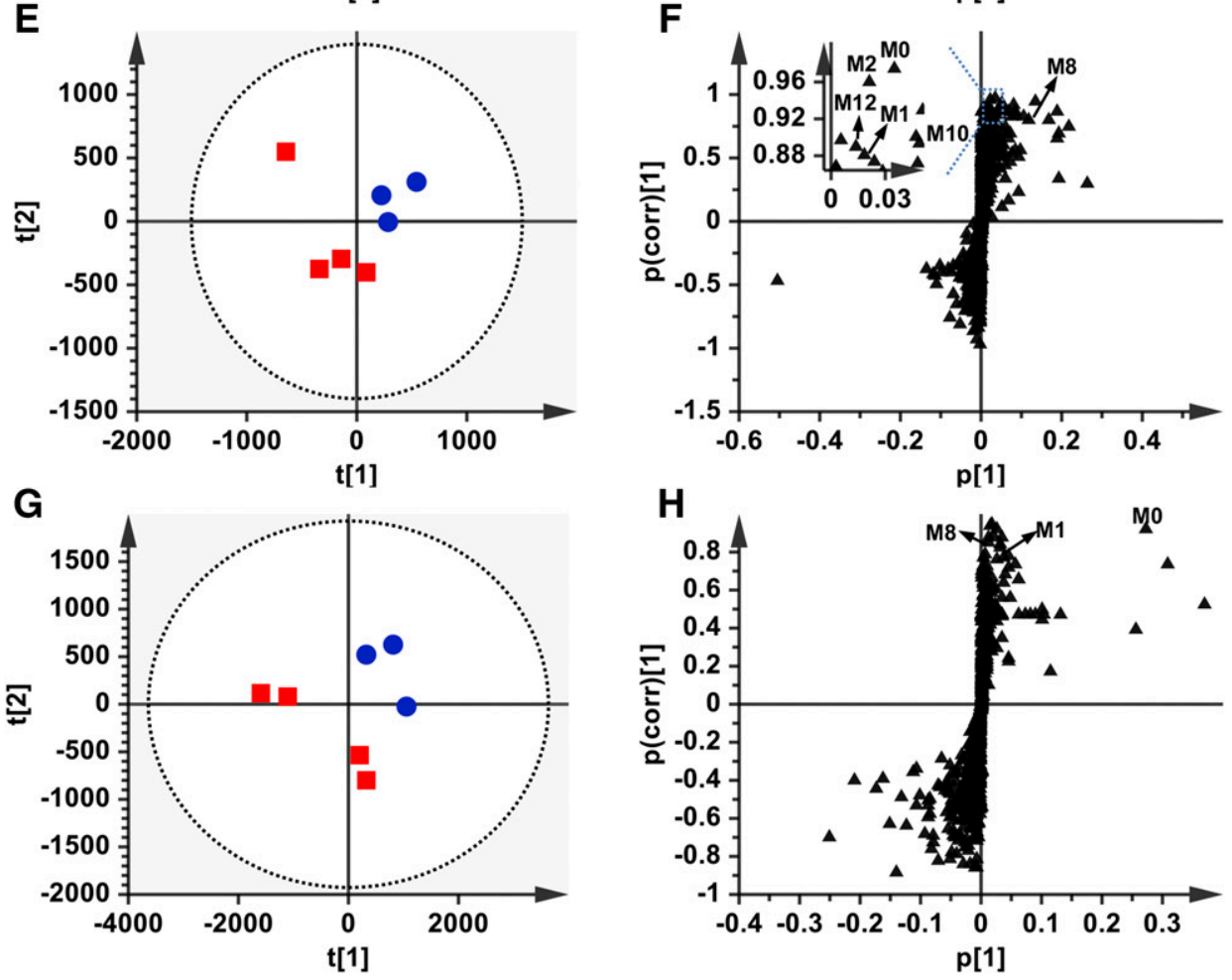

Waters UPLC quadrupole/time-of-flight mass spectrometer (Q/TOF MS; Waters, Milford, MA)

In Vitro Incubation Reaction to Analyze the Metabolic Pathway of PT2385. For liver microsomes, the incubation system $(200 \mu \mathrm{l})$ contained $50 \mathrm{mM}$ Tris- $\mathrm{HCl}$ buffer solution (pH 7.4), $0.5 \mathrm{mg} / \mathrm{ml} \mathrm{HLM}$ or MLM, $5 \mathrm{mM} \mathrm{MgCl}_{2}, 2 \mathrm{mM}$ freshly prepared UDPGA, $25 \mu \mathrm{g} / \mathrm{ml}$ alamethicin, and $10 \mu \mathrm{M}$ PT2385. The mixtures were preincubated at $37^{\circ} \mathrm{C}$ for 3 minutes, and reactions were initiated with $2 \mathrm{mM}$ freshly prepared NADPH. The incubation mixtures without MLM (or HLM), NADPH, UDPGA, and PT2385 were used as the controls. The incubation system for recombinant human CYPs and FMOs was similar to the liver microsome incubation system, except that the microsomes were substituted with $50 \mathrm{nM}$ recombinant enzymes and UDPGA was excluded. The incubation system for recombinant human UGTs contained $50 \mathrm{mM}$ Tris- $\mathrm{HCl}$ buffer solution ( $\mathrm{pH}$ 7.4), $50 \mathrm{nM}$ CYP2C19, $5 \mathrm{mM} \mathrm{MgCl} 2,2 \mathrm{mM}$ UDPGA, $2 \mathrm{mM} \mathrm{NADPH}$, and $10 \mu \mathrm{M}$ PT2385. The reactions were stopped by adding $200 \mu \mathrm{l}$ ice-cold acetonitrile containing $2 \mu \mathrm{M}$ IS after 60 minutes. After centrifugation at $15,000 \mathrm{~g}$ for 10 minutes, a $5 \mu \mathrm{l}$ aliquot of the supernatant was injected into a UPLC Q/TOF MS. The relative abundance (peak area ratio of metabolite/IS) is given. 
TABLE 1

UPLC-HRMS data for PT2385 metabolites detected in mouse feces, urine, bile, and serum

\begin{tabular}{|c|c|c|c|c|c|c|c|}
\hline No. & Metabolic Pathway & $R \mathrm{t}(\min )$ & Measured & Ion & Formula & Error (ppm) & Matrices \\
\hline M0 & Parent & 6.0 & 362.0309 & {$[\mathrm{M}-\mathrm{H}-\mathrm{HF}]^{-}$} & $\mathrm{C}_{17} \mathrm{H}_{12} \mathrm{~F}_{3} \mathrm{NO}_{4} \mathrm{~S}$ & 2.8 & $\mathrm{~F}, \mathrm{U}, \mathrm{S}, \mathrm{B}$ \\
\hline M1 & Hydroxylation & 5.5 & 398.0313 & {$[\mathrm{M}-\mathrm{H}]^{-}$} & $\mathrm{C}_{17} \mathrm{H}_{12} \mathrm{~F}_{3} \mathrm{NO}_{5} \mathrm{~S}$ & 0.8 & $\mathrm{~F}, \mathrm{U}, \mathrm{S}, \mathrm{B}$ \\
\hline M2 & Hydroxylation & 5.7 & 398.0303 & {$[\mathrm{M}-\mathrm{H}]^{-}$} & $\mathrm{C}_{17} \mathrm{H}_{12} \mathrm{~F}_{3} \mathrm{NO}_{5} \mathrm{~S}$ & -1.8 & $\mathrm{~F}, \mathrm{U}, \mathrm{B}$ \\
\hline M3 & $2 \times$ Hydroxylation + desaturation & 5.3 & 412.0156 & {$[\mathrm{M}-\mathrm{H}]^{-}$} & $\mathrm{C}_{17} \mathrm{H}_{10} \mathrm{~F}_{3} \mathrm{NO}_{6} \mathrm{~S}$ & 11.0 & $\mathrm{~F}$ \\
\hline M4 & $2 \times$ Hydroxylation + desaturation & 5.4 & 412.0123 & {$[\mathrm{M}-\mathrm{H}]^{-}$} & $\mathrm{C}_{17} \mathrm{H}_{10} \mathrm{~F}_{3} \mathrm{NO}_{6} \mathrm{~S}$ & 4.9 & $\mathrm{~F}$ \\
\hline M5 & $2 \times$ Hydroxylation + desaturation + methylation & 5.8 & 426.0297 & {$[\mathrm{M}-\mathrm{H}]^{-}$} & $\mathrm{C}_{18} \mathrm{H}_{12} \mathrm{~F}_{3} \mathrm{NO}_{6} \mathrm{~S}$ & 8.8 & $\mathrm{~F}$ \\
\hline M6 & $2 \times$ Hydroxylation + desaturation + methylation & 5.9 & 426.0289 & {$[\mathrm{M}-\mathrm{H}]^{-}$} & $\mathrm{C}_{18} \mathrm{H}_{12} \mathrm{~F}_{3} \mathrm{NO}_{6} \mathrm{~S}$ & 7.0 & $\mathrm{~F}, \mathrm{U}$ \\
\hline M7 & Oxidative defluorination & 5.6 & 380.0421 & {$[\mathrm{M}-\mathrm{H}]^{-}$} & $\mathrm{C}_{17} \mathrm{H}_{13} \mathrm{~F}_{2} \mathrm{NO}_{5} \mathrm{~S}$ & 4.5 & $\mathrm{~F}, \mathrm{~B}$ \\
\hline M8 & Glucuronide conjugation & 5.5 & 558.0701 & {$[\mathrm{M}-\mathrm{H}]^{-}$} & $\mathrm{C}_{23} \mathrm{H}_{20} \mathrm{~F}_{3} \mathrm{NO}_{10} \mathrm{~S}$ & 3.4 & $\mathrm{U}, \mathrm{B}, \mathrm{S}$ \\
\hline M9 & $\mathrm{N}$-acetylcysteine conjugation & 5.8 & 543.0534 & {$[\mathrm{M}-\mathrm{H}]^{-}$} & $\mathrm{C}_{22} \mathrm{H}_{19} \mathrm{~F}_{3} \mathrm{~N}_{2} \mathrm{O}_{7} \mathrm{~S}_{2}$ & 4.8 & $\mathrm{U}$ \\
\hline M10 & Hydroxylation + glucuronide conjugation & 4.8 & 574.0661 & {$[\mathrm{M}-\mathrm{H}]^{-}$} & $\mathrm{C}_{23} \mathrm{H}_{20} \mathrm{~F}_{3} \mathrm{NO}_{11} \mathrm{~S}$ & 5.2 & $\mathrm{U}, \mathrm{B}$ \\
\hline M11 & Hydroxylation + glucuronide conjugation & 5.1 & 574.0661 & {$[\mathrm{M}-\mathrm{H}]^{-}$} & $\mathrm{C}_{23} \mathrm{H}_{20} \mathrm{~F}_{3} \mathrm{NO}_{11} \mathrm{~S}$ & 5.2 & $\mathrm{U}$ \\
\hline M12 & Oxidative defluorination + glucuronide conjugation & 5.0 & 557.0758 & {$[\mathrm{M}-\mathrm{H}]^{-}$} & $\mathrm{C}_{23} \mathrm{H}_{21} \mathrm{~F}_{2} \mathrm{NO}_{11} \mathrm{~S}$ & 5.9 & B \\
\hline
\end{tabular}

F, feces; B, bile; S, serum; U, urine.

UPLC-HRMS Analysis. Metabolite profiling and identification were performed on an Acquity UHPLC/Premier Q/TOF MS (Waters) with an electrospray ionization source. Separation was achieved on an Acquity $\mathrm{C}_{18}$ bridged ethylene hybrid $(\mathrm{BEH})$ UPLC column $(50 \times 2.1 \mathrm{~mm}$ i.d., $1.7 \mu \mathrm{m}$; Waters $)$. The mobile phase consisted of water containing $0.1 \%$ formic acid (A) and acetonitrile containing $0.1 \%$ formic acid (B). The gradient condition was used. The flow rate of the mobile phase was set at $0.4 \mathrm{ml} / \mathrm{min}$. Column temperature was maintained at $40^{\circ} \mathrm{C}$ throughout the run. Data were collected in the negative ion mode on a Q-TOF mass spectrometer, which was operated in a full-scan mode at $m / z 50-850$. Nitrogen was used as both cone gas $(50 \mathrm{l} / \mathrm{h})$ and desolvation gas $(600 \mathrm{l} / \mathrm{h})$. Source desolvation temperatures were set at $120^{\circ} \mathrm{C}$ and $350^{\circ} \mathrm{C}$, respectively. The capillary voltage and cone voltage were 3000 and $20 \mathrm{~V}$, respectively. The structures of metabolites were elucidated by tandem mass spectrometer fragmentography with collision energies ranging from 15 to $40 \mathrm{eV}$.

Data Processing and Multivariate Data Analysis. Progenesis QI software (Waters) was used to deconvolute the chromatographic and mass-spectrometric data. A multivariate data matrix containing information on sample identity, ion identity (retention time and $\mathrm{m} / \mathrm{z}$ ), and ion abundance was generated through centroiding, deisotoping, filtering, peak recognition, and integration. The data matrix was further analyzed using SIMCA version 14.1 software (Umetrics, Kinnelon, NJ). Principle component analysis (PCA) was used to examine separation of the control group and PT2385-treated group. Orthogonal projections to latent structures discriminant analysis (OPLS-DA) was used to analyze the data to identify the major latent variables in the data matrix. Potential metabolites were identified by analyzing the ions contributing to separation of the groups in the loading scatter plots.

Real-Time Polymerase Chain Reaction Analysis. Total RNA from frozen intestine mucosa and liver was extracted with TRIzol reagent (Invitrogen, Carlsbad, CA). cDNA was synthesized from $1 \mu \mathrm{g}$ total RNA using qScript cDNA SuperMix (Gaithersburg, MD). Real-time polymerase chain reaction primer sequences are included in Supplemental Table 1. The relative amount of each mRNA was calculated after normalizing to their corresponding Actb mRNA, and the results were expressed as fold change relative to the control group.

Statistical Analysis. Experiment values were presented as mean \pm S.E.M. Statistical analysis was performed using Prism version 7.0 (GraphPad Software, San Diego, CA). Statistical significance between two groups was determined using two-tailed Student's $t$ test. $P$ values of less than 0.05 were considered to be significant. Power analysis was performed using StatMate version 2.0 (GraphPad Software)

\section{Results}

Metabolomics Analysis to Trace Metabolites for Exposure to PT2385. The chromatographic and mass fragmentation pattern of the reference PT2385 was first investigated. PT2385 eluted at 6.0 minutes (Fig. 1A) with a deprotonated molecular ion at $\mathrm{m} / \mathrm{z}, 382.0365$ in the negative mode; however, the most abundant peak was an in-source fragment ion at $\mathrm{m} / \mathrm{z}, 362.0325$ due to the neutral loss of a hydrogen fluoride moiety (Fig. 1B). The mass spectrometry/mass spectrometry (MS/MS) spectrum of PT2385 gave major fragment ions at $\mathrm{m} / \mathrm{z}$ 347.0089 , 342.0236, 282.0390, 263.0400, 235.0438, and 136.0203 (Fig. 1C), and the tentative fragmentation patterns and ion identification proposed in Fig. 1D. Typically, the fragment ion at $\mathrm{m} / \mathrm{z} 342.0234$ was formed via double dehydrofluorinations, and the $m / z, 347.0089$ ion was formed via the loss of a methyl-free radical beside the sulfonyl combined with dehydrofluorination. The fragment ion at $\mathrm{m} / \mathrm{z} 136.0203$ was characteristic of the fluorobenzonitrile moiety, acting as a diagnostic ion for metabolic elucidation on the fluorobenzonitrile ring.

UPLC-HRMS analysis coupled with multivariate data analysis was used to profile the PT2385 metabolites found in mice. Unsupervised PCA separated the control and PT2385 treatment groups from feces, urine, bile, and serum samples (Fig. 2). The OPLS-DA loading S-plot showed the major ions contributing to the separation containing the parent compound (M0) and metabolites (M1-M12). Detailed information on these metabolites is shown in Table 1.

Metabolite Elucidation in Mice. M1 and M2, detected in serum, feces, urine, and bile, were eluted at 5.5 and 5.7 minutes, respectively. The deprotonated molecular ions at $\mathrm{m} / \mathrm{z} 398.0313$ were 16 Da higher than the parent compound, indicating hydroxylation. The presence of a $\mathrm{m} / \mathrm{z} 151.0067$ fragment ion in the MS/MS spectrum of M1 suggested that the oxygen was introduced in the fluorobenzonitrile moiety (Fig. 3A). M2 gave the major fragments at $\mathrm{m} / \mathrm{z} 378.0247,358.0194$, 330.0266 , and 251.0368 without a dehydration ion, implying the oxygen might be incorporated in the benzene ring bound with a methylsulfonyl group (Fig. 3B).

M3 and M4 were eluted at 5.3 and 5.4 minutes in feces, respectively. They possessed the deprotonated molecular ions at $m / z$ 412.0156, which were 30 Da higher than PT2385, indicating dihydroxylation combined with desaturation. The possible oxidation site might be somewhere in both the benzene rings. The MS/MS fragments and the proposed fragmentation mechanism are shown in Fig. 3C.

M5 and M6 at $\mathrm{m} / \mathrm{z} 426.0297$ were detected at 5.8 and 5.9 minutes in the feces and urine, respectively. The elemental composition corresponded to $\mathrm{C}_{18} \mathrm{H}_{12} \mathrm{~F}_{3} \mathrm{NO}_{6} \mathrm{~S}$, indicated methylation of $\mathrm{M} 3$ and $\mathrm{M} 4$, which was supported by the observation of a typical fragment ion at $\mathrm{m} / \mathrm{z}$. 411.0040 formed by neutral loss of a methyl-free radical in the MS/MS spectrum (Fig. 3D).

M7 was detected in the feces and bile, eluted at 5.6 minutes. The deprotonated molecular ion at $\mathrm{m} / \mathrm{z} 380.0421$, corresponding to the elemental composition of $\mathrm{C}_{17} \mathrm{H}_{13} \mathrm{~F}_{2} \mathrm{NO}_{5} \mathrm{~S}$, was 2 Da lower than that of PT2385. Likewise, its fragment ions at $\mathrm{m} / \mathrm{z}, 360.0315,340.0262$, 233.0468, and 134.0253 were also 2 Da lower than the corresponding 

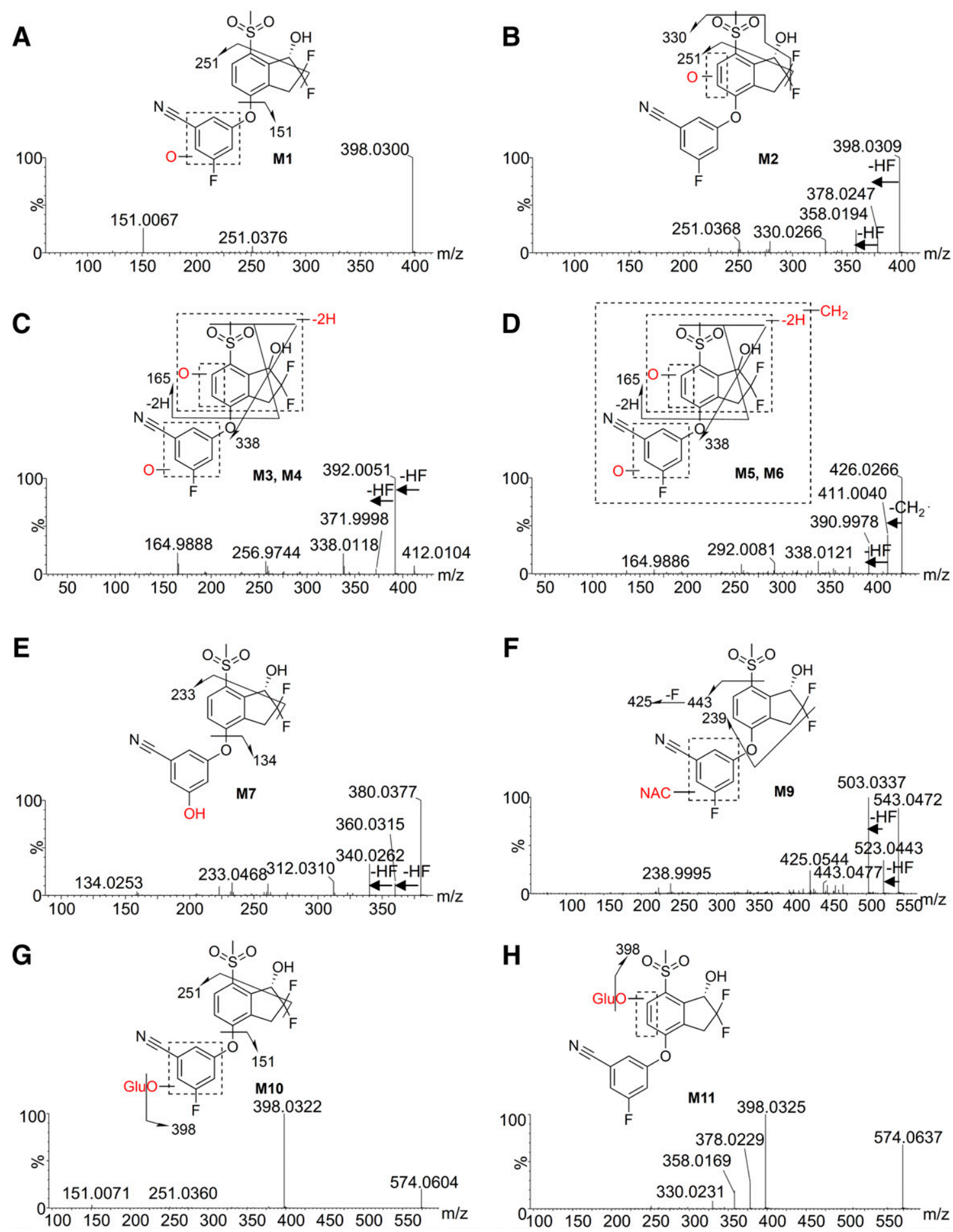

Fig. 3. MS/MS spectra and proposed fragmentation patterns of representative metabolites. (A) M1. (B) M2. (C) M3 and M4. (D) M5 and M6. (E) M7. (F) M9. (G) M10. (H) M11.

fragment ions of PT2385 (Fig. 3E). Analysis of the accurate mass showed that the loss of 2 Da was attributed to defluorination and the incorporation of a hydroxyl group. According to fluorine reactivity in a published report (Xie et al., 2013), this suggested hydroxyl substitution of fluorine in the fluorobenzonitrile portion of the molecule.

M8 exhibited the deprotonated molecular ion at $\mathrm{m} / \mathrm{z}, 558.0701$ at 5.5 minutes in urine, bile, and serum, which was $176 \mathrm{Da}$ higher than that of PT2385, indicative of glucuronidation. In liver microsomal incubations supplemented with UDPGA, M8 was the only metabolite formed, further supporting that M8 is a direct glucuronide conjugate of PT2385. The only possible conjugation position was at the aliphatic hydroxyl group. M9 showed the deprotonated molecular ion at $\mathrm{m} / \mathrm{z}$ 543.0534 at 5.8 minutes in urine, which was $161 \mathrm{Da}$ higher than that of PT2385, indicating a $N$-acetylcysteine conjugate of PT2385. MS/MS fragmentation behavior confirmed that $N$-acetylcysteine was attached to the fluorobenzonitrile moiety (Fig. 3F). M10 and M11 were eluted at 4.8 and 5.1 minutes, respectively, in urine and bile. Their deprotonated molecular ion $(\mathrm{m} / z, 574.0661)$ was $176 \mathrm{Da}$ 


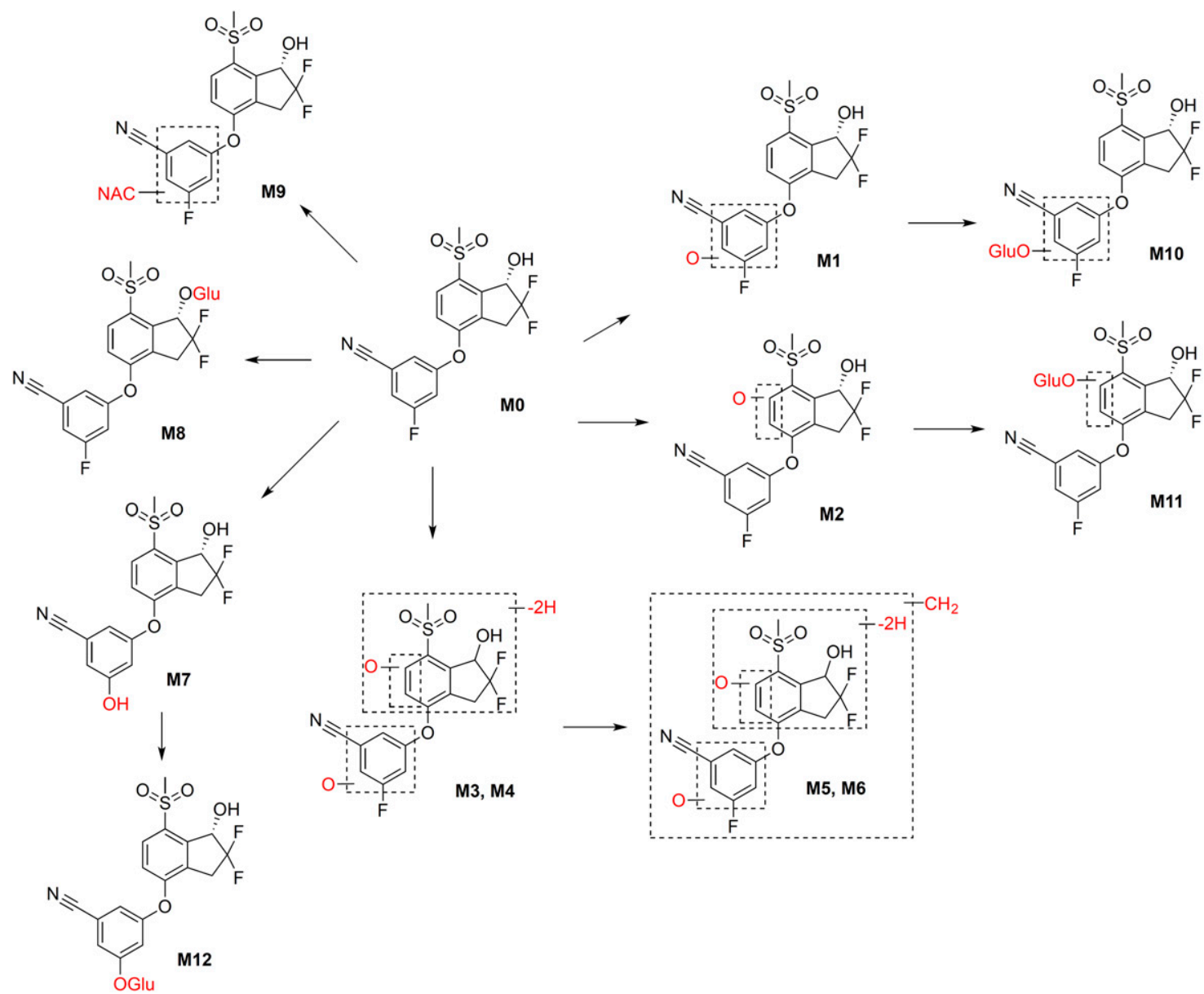

Fig. 4. Proposed metabolic pathways of PT2385 in mice. Biotransformation pathways included hydroxylation (M1, M2), dihydroxylation and desaturation (M3, M4), oxidative defluorination (M7), glucuronidation (M8), $N$-acetylcysteine conjugation (M9), secondary methylation (M5, M6), and glucuronidation (M10, M11, and M12).

higher than that of M1 and M2, suggesting that they were glucuronide conjugates of $\mathrm{M} 1$ and $\mathrm{M} 2$, respectively, most likely at the new phenolic hydroxyl group (Fig. 3, G and H). M12 was detected in the bile and eluted at 5.0 minutes. The deprotonated molecular ion $(\mathrm{m} / \mathrm{z}$ 557.0758) was 176 Da higher than that of M7, indicating that it was a glucuronide conjugate of M7 at the phenolic hydroxyl group. The proposed metabolic pathways of PT2385 in mice are depicted in Fig. 4.

In Vitro Biotransformation of PT2385 by Liver Microsomes. To more fully determine the biotransformation mechanism of PT2385, the metabolism of PT2385 in HLM and MLM was studied. The phase I metabolites M1, M2, M3, M4, and M7 appeared in the NADPHsupplemented incubation systems, but were absent without adding NADPH (Fig. 5, A and B), indicating that the formation of these oxidative metabolites was NADPH dependent. In the presence of UDPGA, M8 was detected. The formation of glucuronide conjugates M10-M12 was only observed in the incubation system with the presence of both UDPGA and NADPH, but was not detected in the system only with NADPH or UDPGA (Fig. 5, A and B). This was consistent with the glucuronide conjugates (M10, M11, and M12) transformed from the oxidative metabolites (M1, M2, and M7), the formation of which required NADPH as a cofactor. HLM and MLM incubations yielded identical metabolic profiles toward PT2385, which demonstrated that mouse may be a suitable animal model to predict PT2385 metabolism and toxicity in humans.
CYP2C19 Is the Predominant Enzyme Responsible for PT2385 Oxidative Metabolism. Identification of the enzymes involved in the biotransformation pathways can facilitate a more complete understanding of an interindividual response to PT2385. Therefore, the catalytic activities of a panel of human recombinant CYP and FMO enzymes toward oxidizing PT2385 were examined. CYP2C19 was identified as the principal isoform that mediated the oxidative metabolism of PT2385, whereas, to a much lesser extent, CYP1A1, CYP1A2, CYP2C9, CYP2D6, and CYP3A4 also catalyzed M1 and M2 formation and CYP1A2 exhibited oxidative defluorination activity to form M7 (Fig. 5, C-E).

Multiple UGTs Participate in PT2385 Glucuronidation. Because several glucuronide conjugates were derived from oxidative metabolites, CYP2C19 and NADPH were included in the recombinant UGT incubation systems. Among all the UGTs examined, UGT2B17, followed by UGT2B7, UGT2B15, and UGT1A6, was involved in the formation of M8 (Fig. 5F); UGT1A1, followed by UGT1A3, UGT1A9, UGT2B15, and UGT2B17, appeared to be responsible for the formation of M10 and M11 (Fig. 5, G and H); and UGT1A1 and UGT1A3, followed by UGT1A9, UGT2B4, UGT2B15, and UGT2B17, played a role in the formation of M12 (Fig. 5I). The generation of various glucuronide conjugates of PT2385 was catalyzed by different subsets of UGTs, implying the existence of different conjugation sites and supporting the view that the structure elucidation was reasonable.

Metabolomics Analysis Revealed Unexpected PT2385-Induced Bile Acid Disruption. To understand the in vivo effects of PT2385, metabolomics analysis was used to profile the endogenous metabolites 


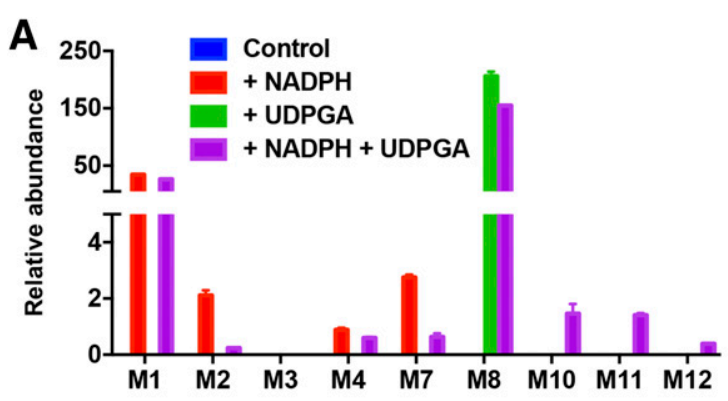

C

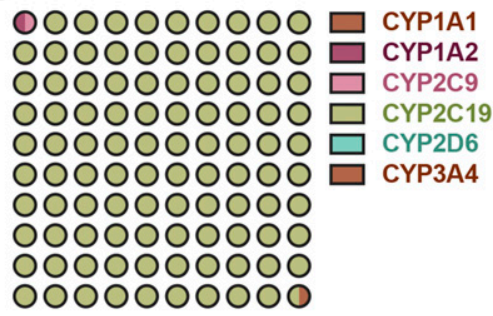

$\mathbf{F}$

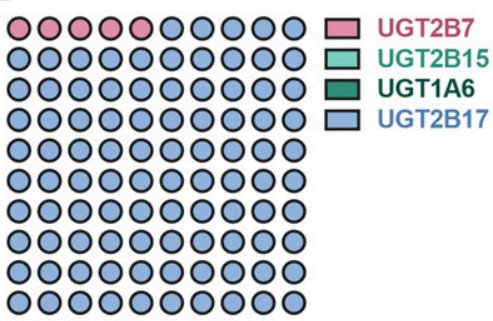

H

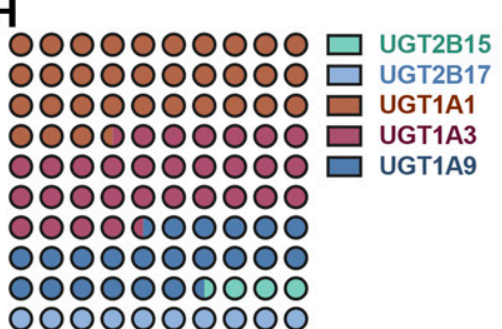

\section{G}

I

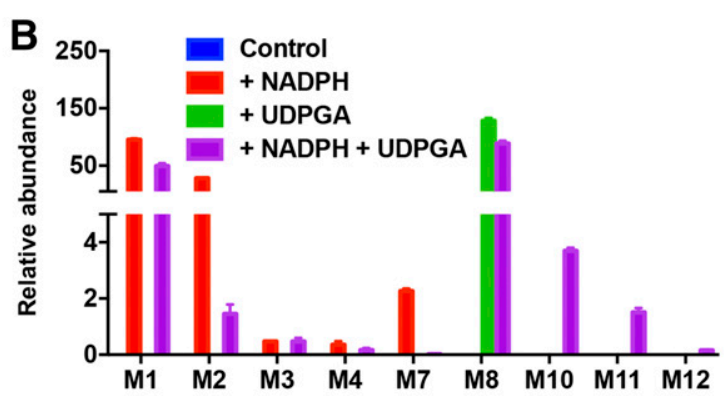

E 0000000000 CYP1A2 0000000000 口 CYP2C19 ००00000000 ००00000000 ०००००००००० ००00000000 ०००००००००० 0000000000 ००00000000 ००००००००००
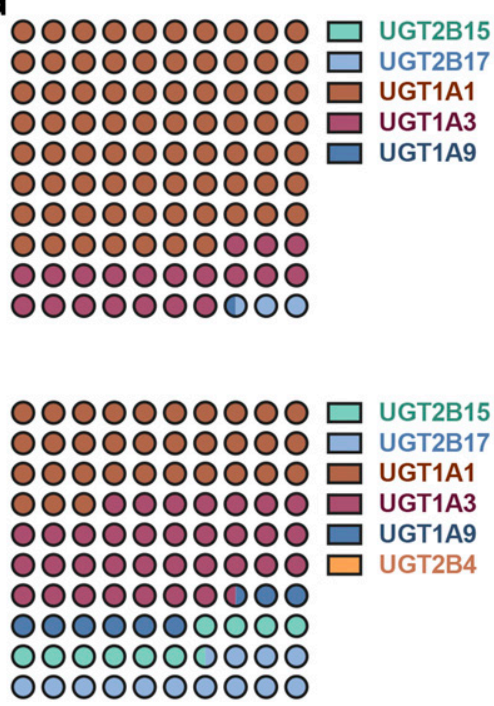

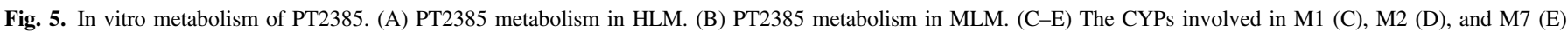
formation. (F-I) The UGTs involved in M8 (F), M10 (G), M11 (H), and M12 (I) formation.

in the 24-hour serum and liver from PT2385-treated mice. Multivariate data analysis was applied to analyze the data sets from both vehicle- and PT2385-treated groups. As expected, PCA modeling of mouse serum showed that samples from PT2385-treated mice clustered away from the controls, indicating notable metabolic changes between these two groups (Fig. 6A). The OPLS-DA-loading S-plot showed that the major ions contributing to the separation displayed the deprotonated molecular ions at $m / z, 514.2842$ and 514.2839 (Fig. 6B). Based on the metabolomics database (https://metlin.scripps.edu/landing_page.php?pgcontent=mainPage), these ions were assumed to be bile acids. The typical $\mathrm{m} / \mathrm{z}$ with the chromatographic retentions and MS/MS spectra indicated that they were TCA and T- $\beta$-MCA, which were further confirmed by comparisons with authentic standards. Likewise, TCA and T- $\beta$-MCA were also the major ions contributing to the separation of liver samples (Fig. 6, C and D). Taken together, PT2385 treatment significantly elevated TCA and T- $\beta$ MCA levels in serum and liver (Fig. 6, E and F).

PT2385 Upregulates Bile Acid Synthesis-Related Gene Expression. To further determine the mechanism for PT2385-induced bile acid disruption, the expression of mRNAs encoding enzymes involved in bile acid synthesis was investigated. The results showed that treatment with PT2385 significantly upregulated Cyp7a1 mRNA encoding CYP7A1, the rate-limiting enzyme in bile acid synthesis (Fig. 7A). Farnesoid $\mathrm{X}$ receptor (FXR) serves as a bile acid sensor and plays an important role in regulation of bile acid homeostasis in enterohepatic circulation (Matsubara et al., 2013). Both hepatic and intestinal FXR controls bile acid transport and synthesis (Li and Chiang, 2015), but PT2385 treatment did not alter either hepatic or intestinal FXR signaling (Fig. 7, B and C). Furthermore, intestine-specific Hif2a ablation substantially upregulated Cyp $7 a 1$ mRNA in liver. These data suggested that PT2385 disrupted bile acid homeostasis through the inhibition of intestinal HIF- $2 \alpha$ signaling.

\section{Discussion}

PT2385 is a selective and potent HIF- $2 \alpha$ inhibitor and showed promising efficacy in the treatment of advanced ccRCC and metabolic 

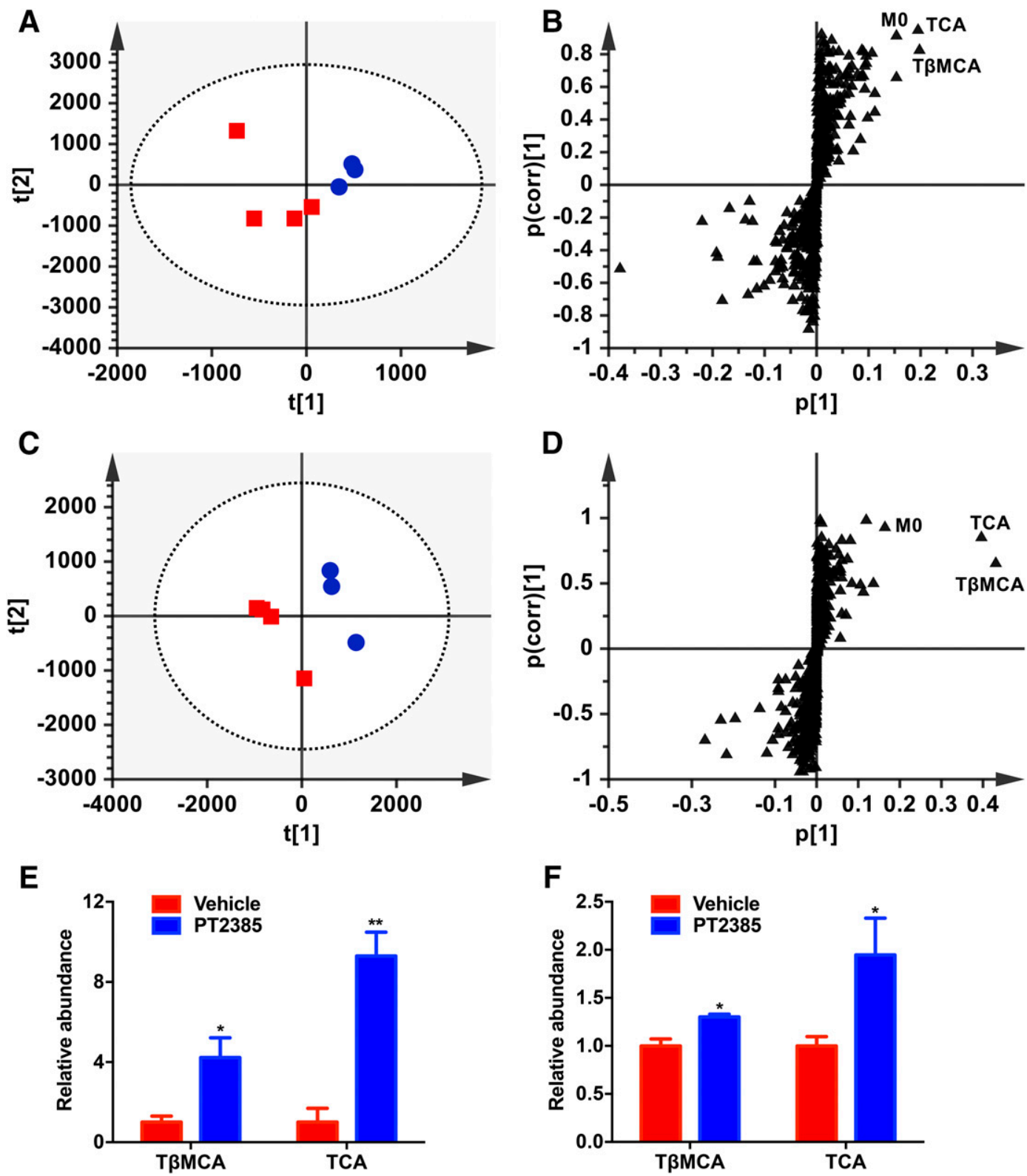

Fig. 6. Multivariate data analysis and endogenic metabolic profiling of PT2385. Samples were collected from mice 24 hours after orally administered with vehicle or PT2385 at a single dose of $50 \mathrm{mg} / \mathrm{kg}$. (A and B) PCA score plot (A) and S-plot (B) of 24-hour serum metabolome. (C and D) PCA score plot (C) and S-plot (D) of liver metabolome. Vehicle (ם) and PT2385 (-). Each point represents an individual mouse sample in PCA score plot and a unique ion in S-plot. (E and F) Relative abundance of TCA and T- $\beta$-MCA in 24-hour serum (E) and liver (F). Data are presented as mean \pm S.E.M. $* P<0.05$; $* * P<0.01$, versus vehicle group, by two-tailed Student's $t$ test.

disease (Wishart, 2016; Xie et al., 2017). PT2385 was rapidly absorbed with a median $t_{\max }$ of 2 hours and a mean $t_{1 / 2}$ of 17 hours in ccRCC patients (Courtney et al., 2017). However, detailed metabolic information is currently publically unavailable. Therefore, in the present study, the metabolic pathways of PT2385 were elucidated with the combined use of in vivo and in vitro models.

PT2385 is extensively metabolized in mice because the parent drug is only a minor component in urine and bile after oral administration to mice. The primary routes of PT2385 biotransformation involve hydroxylation, oxidative defluorination, and glucuronidation. The hydroxylated metabolite M1 and glucuronide conjugate M8 are the major urinary metabolites, and M8 is the major biliary metabolite. The parent drug is the most abundant drug-related material in feces, which could be largely attributed to the unabsorbed PT2385 fraction.
The circulating drug-related metabolites are mainly composed of the unmodified PT2385 and, to a much lesser extent, M1 and M8. Thus, it is less likely that M1 and M8 contribute to the pharmacological and toxicological effects of PT2385. Results from HLM and MLM experiments suggest that the mouse is a reasonable surrogate for predicting metabolism of this drug in humans. It should be noted that only male mice were used in the current study because all of the published preclinical studies for PT2385 and its analog PT2399 were done with males (Cho et al., 2016; Wallace et al., 2016).

Another important task in preclinical drug metabolism studies is phenotyping the enzymes involved in PT2385 metabolism, which facilitates the understanding of individual's response and could predict drug-drug interactions. The in vitro incubations of PT2385 with recombinant human phase I-metabolizing enzymes revealed that 


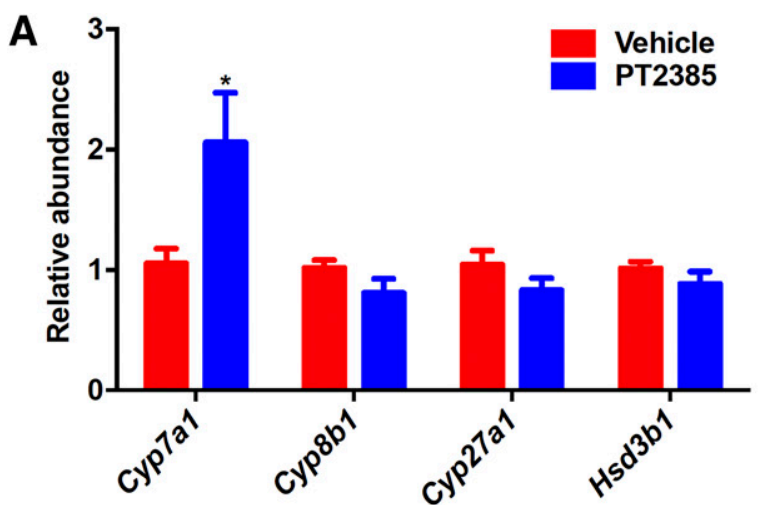

B
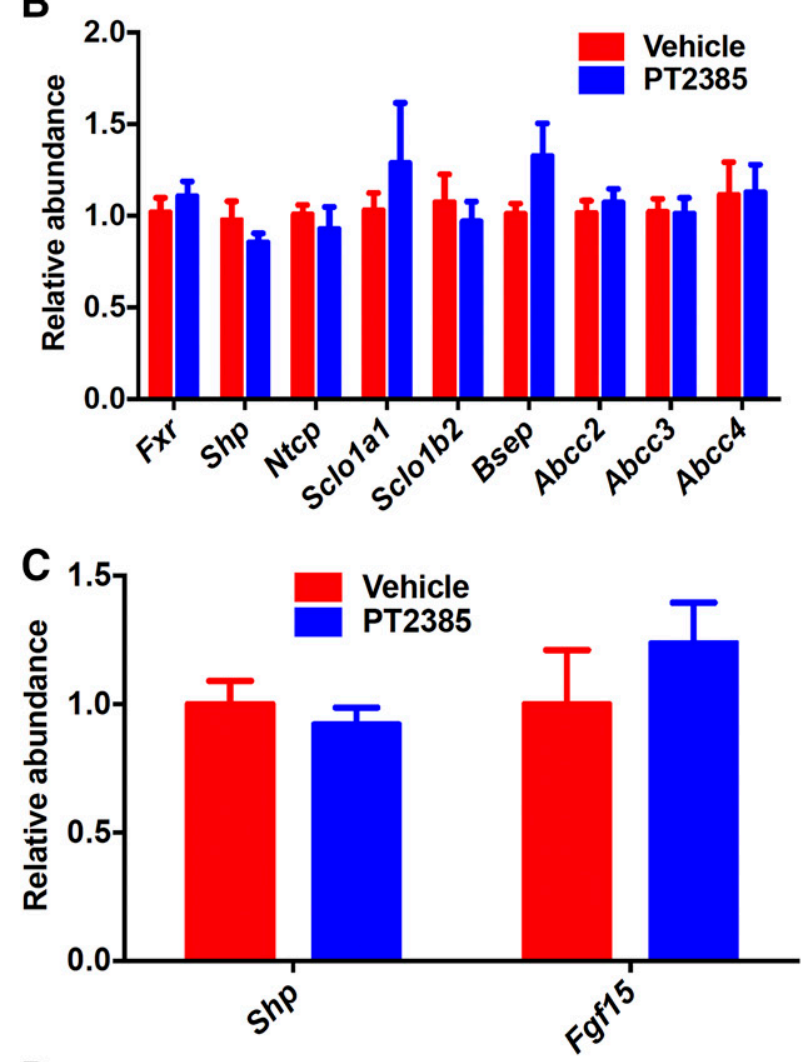

D

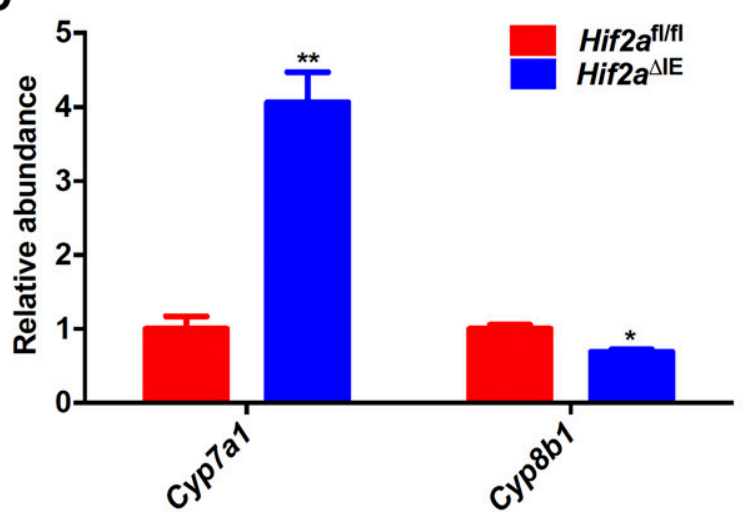

Fig. 7. PT2385 treatment upregulates bile acid synthesis. (A) Bile acid synthesis mRNAs in the livers after PT2385 exposure. (B) FXR and its target gene mRNAs in mouse liver after PT2385 exposure. (C) FXR and its target gene mRNAs in mouse intestine after PT2385 exposure. (D) Bile acid synthesis mRNAs in the livers of $H i f 2 a^{\mathrm{fl} / f \mathrm{fl}}$ and $H i f 2 a^{\Delta \mathrm{IE}}$ mice. Data are presented as mean \pm S.E.M. $* P<0.05 ; * * P<0.01$, versus vehicle group or Hif $2 a^{\mathrm{fl} / \mathrm{fl}}$ mice, by two-tailed Student's $t$ test. multiple enzymes, including CYP2C19, CYP1A1, CYP1A2, CYP2D6, CYP2C9, and CYP3A4, participate in the hydroxylation of PT2385. Among these enzymes, CYP2C19 is the predominant CYP involved in PT2385 oxidation. CYP2C19 plays a critical role in the metabolism of drugs, including anticancer, antidepressant, antihypertensive, antiplatelet, and antiulcer drugs (Hirota et al., 2013). However, CYP2C19 is polymorphic with $12 \%-23 \%$ of null alleles in Asians and 3\%-5\% in Caucasians, leading to significant interindividual differences in activity that could result in different metabolism rates and fluctuations in exposure levels of PT2385 (Goldstein and de Morais, 1994; Umamaheswaran et al., 2014). For phase II metabolism, there were UGT1A family glucuronidate phenol metabolites (M1, M2, and M7), with UGT1A1/3 responsible for M10 and M12 formation, and UGT1A1/3/9 for M11 formation. UGT1A catalyzes the glucuronidation of a wide range of substrates, including endogenous substrates such as bilirubin, bile acids, and steroids, as well as drugs and environment pollutants (Rowland et al., 2013). Moreover, UGT2B17 dominates the direct glucuronide conjugation of the aliphatic hydroxyl group in PT2385 to M8. UGT2B17 is mainly expressed in the liver with very low expression in the small intestine and kidney (Nakamura et al., 2008). M8 is the most abundant metabolite found in bile, which is formed in liver and quickly excreted in bile. It was also reported that UGT2B17 exhibited high expression in jejunum of morbidly obese subjects and had the high interindividual variation, which might be the result of a genetic polymorphism (Miyauchi et al., 2016). Furthermore, the activity of UGT2B17 is also significantly impacted by complex factors, such as age, hormonal signaling, medications, supplements, alcohol consumption, and smoking (Neumann et al., 2016). Therefore, there might be significant interpatient variability in drug metabolism in populations and drug-drug interactions of PT2385, perhaps leading to increased toxicity or altered efficacy. Consistently, pharmacokinetic variability was observed in patients treated with PT2385 in the current phase I doseescalation study (Courtney et al., 2017). To reduce this variability, PT2977 was developed with more potency than PT2385, and is in a phase II trial in patients with advanced renal tumors.

Metabolomics analysis also revealed that PT2385 disrupted bile acid homeostasis, as shown by notably increased TCA and T- $\beta$-MCA in mice after PT2385 administration. TCA and T- $\beta$-MCA are major primary bile acids, constituting about $60 \%$ of the taurine-conjugated bile acids and $18 \%$ of total bile acids in mice (García-Cañaveras et al., 2012). The elevated TCA and T- $\beta$-MCA levels observed indicate that PT2385 may induce cholestasis after long-term application. It was reported that the ligand-activated nuclear receptor FXR mainly regulates bile acid synthesis enzymes and transporters by a complex network of transcriptional cascades (Eloranta and Kullak-Ublick, 2005). CYP7A1 catalyzes the first reaction in the cholesterol catabolic pathway in liver and is the rate-limiting step in bile acid synthesis (Chiang, 2009). The expression of CYP7A1 is repressed by either SHP via liver FXR activation or FGF15 via intestine FXR activation (Goodwin et al., 2000; Inagaki et al., 2005). However, transcriptional analysis for bile acid synthesis genes reveals that, among FXR and its target gene mRNAs in liver and intestine, only the expression of Cyp7al mRNA in livers is upregulated by PT2385 treatment. Moreover, Cyp7al mRNA levels are also increased in the livers of intestinal-specific Hif2a knockout mice. These data imply that PT2385 might upregulate liver CYP7A1 by inhibiting intestinal HIF- $2 \alpha$, independent of FXR signaling. Others reported that activation of hepatic HIF- $2 \alpha$ leads to the inhibition of CYP7A1 by repressing the circadian expression of Rev-erb $\alpha$, resulting in increased expression of E4BP4, a negative regulator of CYP7A1 (Ramakrishnan et al., 2014). However, neither PT2385 treatment nor intestinal Hif2a disruption affects hepatic HIF- $2 \alpha$ signaling (Xie et al., 2017). The link 
between intestine HIF- $2 \alpha$ and bile acid synthesis needs further investigation.

In conclusion, this study is the first report on PT2385 metabolism and its modulation of bile acid homeostasis. The metabolites from PT2385 are mainly derived from CYP2C19-mediated hydroxylation and oxidative defluorination and UGT2B17- and UGT1A1/3-mediated glucuronidation. The genetic polymorphisms of CYP2C19 and UGT2B17 may explain potential individual variation observed during its clinical trials. Intestinal HIF-2 $\alpha$ inhibition by PT2385 treatment disrupts bile acid homeostasis in mice. The potential safety issues regarding long-term use of PT2385 need further assessment. Continued investigation into the connection between intestine HIF- $2 \alpha$ and bile acid synthesis will be helpful in understanding the function of intestinal HIF- $2 \alpha$. Taken together, the information provided in the present study reveals potential drug-organism interactions for PT2385, expands the drug substrate spectra for CYP2C19 and UGT2B17, and thus could be beneficial for further development of PT2385 or its structural analogs.

\section{Authorship Contributions}

Participated in research design: Xie, Gao, Qin, Gonzalez.

Conducted experiments: Xie, Gao, Sun, Zhang, Krausz.

Contributed new reagents or analytic tools: Xie, Gao.

Performed data analysis: Xie, Gao.

Wrote or contributed to the writing of the manuscript: Xie, Gao, Gonzalez.

\section{References}

Bertout JA, Majmundar AJ, Gordan JD, Lam JC, Ditsworth D, Keith B, Brown EJ, Nathanson KL, and Simon MC (2009) HIF2alpha inhibition promotes p53 pathway activity, tumor cell death, and radiation responses. Proc Natl Acad Sci USA 106:14391-14396.

Chen W, Hill H, Christie A, Kim MS, Holloman E, Pavia-Jimenez A, Homayoun F, Ma Y, Patel N, Yell P, et al. (2016) Targeting renal cell carcinoma with a HIF-2 antagonist. Nature 539 $112-117$

Chiang JY (2009) Bile acids: regulation of synthesis. J Lipid Res 50:1955-1966.

Cho H, Du X, Rizzi JP, Liberzon E, Chakraborty AA, Gao W, Carvo I, Signoretti S, Bruick RK, Josey JA, et al. (2016) On-target efficacy of a HIF- $2 \alpha$ antagonist in preclinical kidney cancer models. Nature 539:107-111.

Courtney KD, Infante JR, Lam ET, Figlin RA, Rini BI, Brugarolas J, Zojwalla NJ, Lowe AM, Wang K, Wallace EM, et al. (2017) Phase I dose-escalation trial of PT2385, a first-in-class hypoxia-inducible factor- $2 \alpha$ antagonist in patients with previously treated advanced clear cell renal cell carcinoma. J Clin Oncol DOI: 10.1200/JCO.2017.74.2627 [published ahead of print].

Eloranta JJ and Kullak-Ublick GA (2005) Coordinate transcriptional regulation of bile acid homeostasis and drug metabolism. Arch Biochem Biophys 433:397-412.

Epstein AC, Gleadle JM, McNeill LA, Hewitson KS, O'Rourke J, Mole DR, Mukherji M, Metzen E, Wilson MI, Dhanda A, et al. (2001) C. elegans EGL-9 and mammalian homologs define a family of dioxygenases that regulate HIF by prolyl hydroxylation. Cell 107:43-54.

Fang ZZ and Gonzalez FJ (2014) LC-MS-based metabolomics: an update. Arch Toxicol 88: $1491-1502$.

García-Cañaveras JC, Donato MT, Castell JV, and Lahoz A (2012) Targeted profiling of circulating and hepatic bile acids in human, mouse, and rat using a UPLC-MRM-MS-validated method. $J$ Lipid Res 53:2231-2241.

Gnarra JR, Tory K, Weng Y, Schmidt L, Wei MH, Li H, Latif F, Liu S, Chen F, Duh FM, et al (1994) Mutations of the VHL tumour suppressor gene in renal carcinoma. Nat Genet 7:85-90.

Goldstein JA and de Morais SM (1994) Biochemistry and molecular biology of the human CYP2C subfamily. Pharmacogenetics 4:285-299.

Goodwin B, Jones SA, Price RR, Watson MA, McKee DD, Moore LB, Galardi C, Wilson JG, Lewis MC, Roth ME, et al. (2000) A regulatory cascade of the nuclear receptors FXR, SHP-1, and LRH-1 represses bile acid biosynthesis. Mol Cell 6:517-526.

Gordan JD, Bertout JA, Hu CJ, Diehl JA, and Simon MC (2007) HIF-2alpha promotes hypoxic cell proliferation by enhancing c-myc transcriptional activity. Cancer Cell 11:335-347.
Hirota T, Eguchi S, and Ieiri I (2013) Impact of genetic polymorphisms in CYP2C9 and CYP2C19 on the pharmacokinetics of clinically used drugs. Drug Metab Pharmacokinet 28:28-37.

Inagaki T, Choi M, Moschetta A, Peng L, Cummins CL, McDonald JG, Luo G, Jones SA, Goodwin B, Richardson JA, et al. (2005) Fibroblast growth factor 15 functions as an enterohepatic signal to regulate bile acid homeostasis. Cell Metab 2:217-225.

Keith B, Johnson RS, and Simon MC (2011) HIF1 $\alpha$ and HIF2 $\alpha$ : sibling rivalry in hypoxic tumour growth and progression. Nat Rev Cancer 12:9-22.

Kondo K, Klco J, Nakamura E, Lechpammer M, and Kaelin WG, Jr (2002) Inhibition of HIF is necessary for tumor suppression by the von Hippel-Lindau protein. Cancer Cell 1:237-246.

Li T and Chiang JY (2015) Bile acids as metabolic regulators. Curr Opin Gastroenterol 31 $159-165$.

Matsubara T, Li F, and Gonzalez FJ (2013) FXR signaling in the enterohepatic system. Mol Cell Endocrinol 368:17-29.

Maxwell PH, Wiesener MS, Chang GW, Clifford SC, Vaux EC, Cockman ME, Wykoff CC, Pugh CW, Maher ER, and Ratcliffe PJ (1999) The tumour suppressor protein VHL targets hypoxiainducible factors for oxygen-dependent proteolysis. Nature 399:271-275.

Meijer J, Bergstrand A, and DePierre JW (1987) Preparation and characterization of subcellular fractions from the liver of C57BL/6 mice, with special emphasis on their suitability for use in studies of epoxide hydrolase activities. Biochem Pharmacol 36:1139-1151.

Miyauchi E, Tachikawa M, Declèves X, Uchida Y, Bouillot JL, Poitou C, Oppert JM, Mouly S, Bergmann JF, Terasaki T, et al. (2016) Quantitative atlas of cytochrome P450, UDPglucuronosyltransferase, and transporter proteins in jejunum of morbidly obese subjects. Mol Pharm 13:2631-2640.

Muglia VF and Prando A (2015) Renal cell carcinoma: histological classification and correlation with imaging findings. Radiol Bras 48:166-174.

Nakamura A, Nakajima M, Yamanaka H, Fujiwara R, and Yokoi T (2008) Expression of UGT1A and UGT2B mRNA in human normal tissues and various cell lines. Drug Metab Dispos 36 1461-1464.

Neumann E, Mehboob H, Ramírez J, Mirkov S, Zhang M, and Liu W (2016) Age-dependent hepatic UDP-glucuronosyltransferase gene expression and activity in children. Front Pharmacol 7:437.

Ramakrishnan SK, Taylor M, Qu A, Ahn S-H, Suresh MV, Raghavendran K, Gonzalez FJ, and Shah YM (2014) Loss of von Hippel-Lindau protein (VHL) increases systemic cholesterol levels through targeting hypoxia-inducible factor $2 \alpha$ and regulation of bile acid homeostasis. Mol Cell Biol 34:1208-1220.

Rowland A, Miners JO, and Mackenzie PI (2013) The UDP-glucuronosyltransferases: their role in drug metabolism and detoxification. Int J Biochem Cell Biol 45:1121-1132.

Sato Y, Yoshizato T, Shiraishi Y, Maekawa S, Okuno Y, Kamura T, Shimamura T, Sato-Otsubo A Nagae G, Suzuki H, et al. (2013) Integrated molecular analysis of clear-cell renal cell carcinoma. Nat Genet 45:860-867.

Semenza GL and Wang GL (1992) A nuclear factor induced by hypoxia via de novo protein synthesis binds to the human erythropoietin gene enhancer at a site required for transcriptional activation. Mol Cell Biol 12:5447-5454.

Siegel RL, Miller KD, and Jemal A (2017) Cancer statistics, 2017. CA Cancer J Clin 67:7-30.

Umamaheswaran G, Kumar DK, and Adithan C (2014) Distribution of genetic polymorphisms of genes encoding drug metabolizing enzymes \& drug transporters - a review with Indian perspective. Indian J Med Res 139:27-65.

Vanharanta S, Shu W, Brenet F, Hakimi AA, Heguy A, Viale A, Reuter VE, Hsieh JJ, Scandura JM, and Massagué J (2013) Epigenetic expansion of VHL-HIF signal output drives multiorgan metastasis in renal cancer. Nat Med 19:50-56.

Wallace EM, Rizzi JP, Han G, Wehn PM, Cao Z, Du X, Cheng T, Czerwinski RM, Dixon DD, Goggin BS, et al. (2016) A small-molecule antagonist of HIF2 $\alpha$ is efficacious in preclinical models of renal cell carcinoma. Cancer Res 76:5491-5500.

Wishart DS (2016) Emerging applications of metabolomics in drug discovery and precision medicine. Nat Rev Drug Discov 15:473-484.

Xie C, Yagai T, Luo Y, Liang X, Chen T, Wang Q, Sun D, Zhao J, Ramakrishnan SK, Sun L, et al. (2017) Activation of intestinal hypoxia-inducible factor $2 \alpha$ during obesity contributes to hepatic steatosis. Nat Med 23:1298-1308.

Xie C, Zhong D, Yu K, and Chen X (2012) Recent advances in metabolite identification and quantitative bioanalysis by LC-Q-TOF MS. Bioanalysis 4:937-959.

Xie C, Zhou J, Guo Z, Diao X, Gao Z, Zhong D, Jiang H, Zhang L, and Chen X (2013) Metabolism and bioactivation of famitinib, a novel inhibitor of receptor tyrosine kinase, in cancer patients. Br J Pharmacol 168:1687-1706.

Address correspondence to: Dr. Frank J. Gonzalez, Laboratory of Metabolism, Center for Cancer Research, National Cancer Institute, National Institutes of Health, Bethesda, MD 20892. E-mail: gonzalef@mail.nih.gov; or Dr. Xiaoxia Gao, Modern Research Center for Traditional Chinese Medicine, Shanxi University, Taiyuan, Shanxi, 030006, China. Email: gaoxiaoxia@sxu.edu.cn 